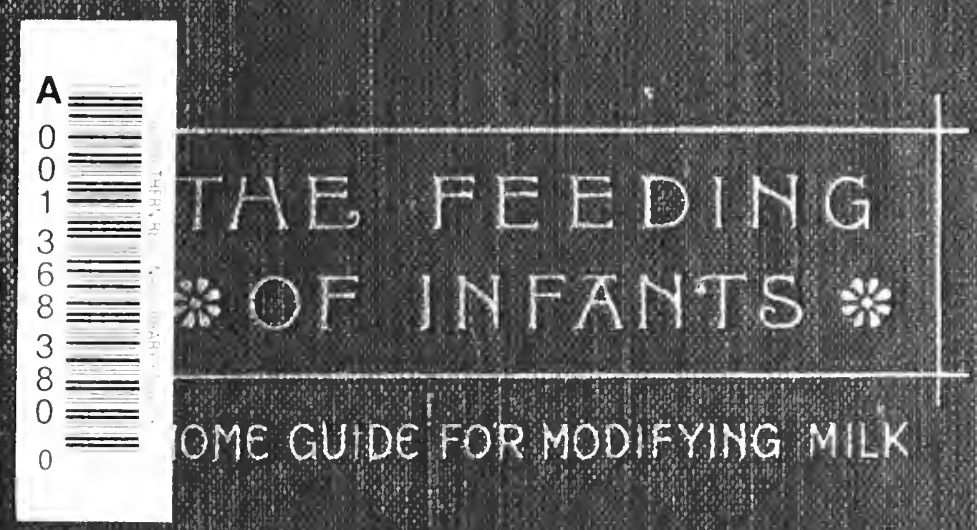

4

Joseph E. WINTERS, M.O. 


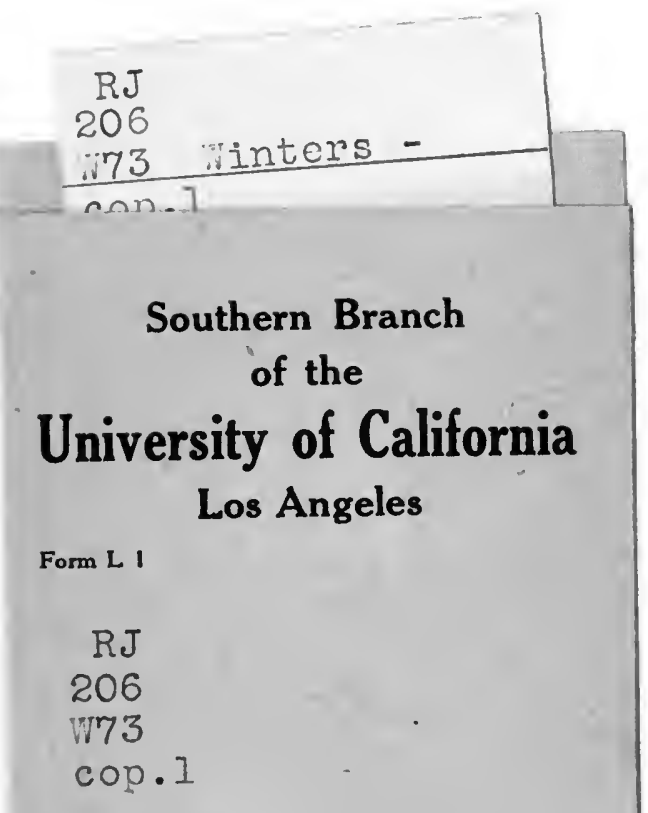


This book is DUE on the last date stamped below

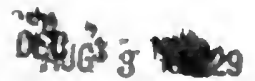

\section{AUE 31928 \\ mits : 5 iofi}


Digitized by the Internet Archive in 2007 with funding from Microsoft Corporation 


\title{
THE FEEDING OF INFANTS
}

\section{HOME GUIDE FOR MODIFYING MILK}

\author{
BY \\ Joseph E. Winters, M.D. \\ PROFESSOR OF DISEASES OF CHILDREN, CORNELL \\ UNIVERSITY MEDICAL COLLEGE \\ $25 / 22$
}

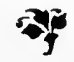

\author{
NEW YORK \\ E. P. DUTTON \& COMPANY \\ 31 WEST TWENTY-THIRD STREET \\ 1901
}


COPYRIGHT, IgOI

BY

E. P. DUTTON \& CO.

Tbe tknfckerbocker Dress, Hew lork 


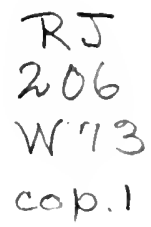

TO

ALL LITTLE CHILDREN

WHOSE WELFARE IS

CLOSEST TO MY HEART

I DEDICATE THE FOLLOWING PAGES 



\section{INTRODUCTION}

Tile fundamental guides in the feeding of infants are the composition of human milk, the amount of milk secreted by the breasts of a healthy nursing woman, and the capacity of the stomach of the infant.

The correct composition of human milk was discovered by Dr. Arthur V. Meigs, of Philadelphia, in I882. His father, the late Dr. J. Forsyth Meigs, by repeated and untiring investigations, determined accurately the amount of milk secreted by the breasts of a healthy nursing woman. 
In i 872 , Frolowsky, of Russia, published measurements made after death of the capacity of the stomach of infants at different ages.

It is now nineteen years since the last of these investigations was published. Notwithstanding this fact, there has been no dissemination of the central, cardinal principles on which the proper feeding of infants is founded. These three essentials are fully considered in the text of this work, and they should be familiar to every mother and nurse.

On pages 13 to 17 I have arranged charts, based on long experience and repeated analyses of milk and cream, that will enable any one to prepare food of 
definite percentages for infants of different ages-from birth to the end of the first year.

Joseph E. Winters, M.D.

New York, 25 West 37 th St.

January, I 90I. 



\section{Feeding of Infants}

\section{Home Guide for Modifying Milk}$$
25 / 22
$$

Two facts should be ever present in the mind when considering the feeding of infants.

First: Of children born healthy, and exclusively breast-fed, very few die during the first year of life, even in institutions, or among the poor in tenements; a breast-fed infant is seldom ill, rarely coming under a physician's care until after the period of weaning.

Second: Of children artificially fed, in institutions and in tene- 
ments, very few survive the first year.

In these two immutable facts we have consummate proof that mother's milk is the ideal food for infants.

When this is impracticable, the only method by which we can establish the value of an artificial substitute, is to compare it with wor'an's milk.

A substitute for human milk must resemble that perfect model as closely as possible, in chemical composition and physiological properties.

This is an infallible law in artificial feeding. It is emphasized by the following records. In Germany the Government requires that the death certificate of an infant under one year of age shall state what the mode of feeding has been. These 


\section{Modifying Milk}

records show that 8 per cent. of children, exclusively nourished by mothers, die during the first year of life. Of children fed on artificial foods, 5 I per cent. die during the first year.

The mortality in the Berlin Charity Hospital ranges from 59 to 93 per cent.

In the Buda-Pesth Foundling Hospital, during twelve years, the mortality has never exceeded I 5 per cent.

In the former institution the children are artificially fed, in the latter, with few exceptions, the mother nurses her child.

It is my purpose to show that this enormous difference in mortality between natural and artificial feeding is preventable.

Among the intelligent upper classes, where artificial feeding is now carried out on scientific 
$4 \quad$ Feeding of Infants

lines, the artificially fed infant usually thrives.

In institutions and in tenements, it is an ever-changing, fortuitous system that is practised. It is not infrequent to find that a dozen foods have been tried in as many weeks, and all with equally disastrous results.

An artificial food for an infant must fulfil the following requirements.

First: It must contain all the constituents which are found in human milk.

Second: These constituents must be present in the same proportions as in human milk.

Third: It must contain nothing that is not found in human milk.

Fourth: It must be of animal origin. 
Fifth : It must be fresh.

Infraction of these laws is the cause of the excessive mortality from artificial feeding. The last three are frequently disregarded, but never with impunity.

The only universally available food that can be made to meet these five essential conditions is cow's milk.

Until within a comparatively recent period, however, cow's milk has often proved disastrous as a food for infants. The cause of this and its elucidation were discovered by Dr. Arthur V. Meigs, of Philadelphia, in I882, when he made known to the medical profession for the first time the accurate percentages of the various constituents contained in human milk. He discovered that human milk 
contains I per cent. of caseine, or proteid. ${ }^{1}$

Previous analyses had made the percentages of this constituent too high. (This is the constituent of milk which produces the curd when coagulation takes place.) It is the large proportion of caseine, or curd, in cow's milk, that makes it, when undiluted, so difficult for infants to digest.

Cow's milk contains 4 per cent. of proteid.

Human milk contains I per cent. of proteid.

RELATIVE PROPORTIONS OF THE

CHIEF CONSTITUENTS CON. TAINED IN HUMAN AND

COW'S MILK.

Human Milk.

Fat $\ldots \ldots \ldots \ldots \ldots \ldots+.6 \%$

Milk-sugar............ 7.00$\}$ approximate.

Proteids .............. . oo

1 Caseine, albuminoid, and proteid are synonymous. 


\section{Modifying Milk}

Cow's MiLK.

Fat ...................

Milk-sugar............4.50 approximate.

Proteids .............4.00

Consequently, to make cow's milk a suitable food for infants, it must be so diluted as to contain I per cent. of proteid.

Cow's milk so diluted becomes deficient in fat and milk-sugar; these have to be supplied.

The following exemplifies this statement :

Cow's Milk Diluted.

Milk I part, water 3 parts.

Fat $\ldots \ldots \ldots \ldots \ldots \ldots \ldots \ldots \ldots+1.00$

Milk-sugar.............1.12 $\}$ approximate.

Proteids................ . oo

In human milk, fat and milksugar are greatly in excess of the proteids; in cow's milk, these three constituents are in nearly equal proportions.

Cream, like human milk, contains a high percentage of fat, 
S

with a low percentage of proteids. With cream, or super-fatted milk, milk-sugar and boiling water, we can with facility prepare a food of any given percentages that the infant's age or digestive power may call for. For early infancy, when a low percentage of proteids is required, it is necessary to have cream with a very high percentage of fat.

We often find that for the first few days of life, the proteids must be reduced to one half of $I$ per cent., or even one quarter of I per cent., until the child's strimach becomes accustomed to the digestion of this constituent.

Many of the failures in homemodification are undoubtedly the result of not giving explicit directions as to the length of time after milking when the cream should be removed from the milk, 


\section{Modifying Milk}

and as to the quantity that should be taken from each quart bottle.

For infant feeding it makes a decided difference as to the amount of top milk that is taken from each quart of milk.

In order to determine accurately the percentages of fat and proteids in different cream layers in a quart bottle of milk, I had numerous analyses made by Prof. Adriance. I have had these analyses repeated by Dr. Lederle, of the New York Health Board, and by Mr. Henry C. Sherman, at Columbia University.

These analyses were made with a view of determining the value of a conviction, based upon clinical experiences in the feeding of infants, that the upper cream layers contain a comparatively low percentage of proteids, with the 
result that such conviction was confirmed in every instance by the analyses.

In metropolitan centres, all milk reaches the consumer, practically speaking, sixteen or more hours after the time of milking.

The upper ounce from a quart of such milk shows the following composition :

Fat..........23.80 per cent.

Milk-sugar ...... 3.90

Proteids........ 2.90 “ " “

The upper four ounces from a quart of milk sixteen or more hours after milking show the following composition :

Fat...........2r.so per cent.

$\begin{array}{llll}\text { Milk-sugar...... } & 4.00 & \text { " } & \text { “" } \\ \text { Proteids....... } & 3.00 & \text { " }\end{array}$

The upper eight ounces from a quart of milk sixteen or more 
hours after milking show the following composition :

Fat........... 7.00 per cent.

Milk-sugar ..... 4.30 “ “ "“

Proteids......... 3.10 “ "،

With the above instructions and analyses, it is easy to prepare a food of any desired percentages.

During the early days of infancy no more than 0.25 per cent. of proteids should be given, and no less than 2 per cent. of fat. With these low percentages it is practicable to feed an infant the first day of its life artificially, without any disturbance of digestion. I state this positively, from a large experience in laboratory feeding, where the percentages are accurate.

Infants so fed do not lose weight the first week of life, as they formerly did, when two or 
three days were allowed to elapse, before the use of food or of breast milk was begun.

The following tables give explicit directions for the preparation of food for infants of different ages. ${ }^{1}$

During the summer months the strengthening of the food should be more gradual than has been indicated in these formula.

An infant of three or four months will not, as a rule, digest more than I per cent. of proteids in hot weather.

Many of the digestive derangements incident to this period may be averted by increasing the proportion of lime water to one fourth of the total quantity during the heated term.

1 Human milk is alkaline, cow's milk is acid ; this necessitates the addition of an alkali to the mixture; lime water is used for this purpose. 
Modifying Milk

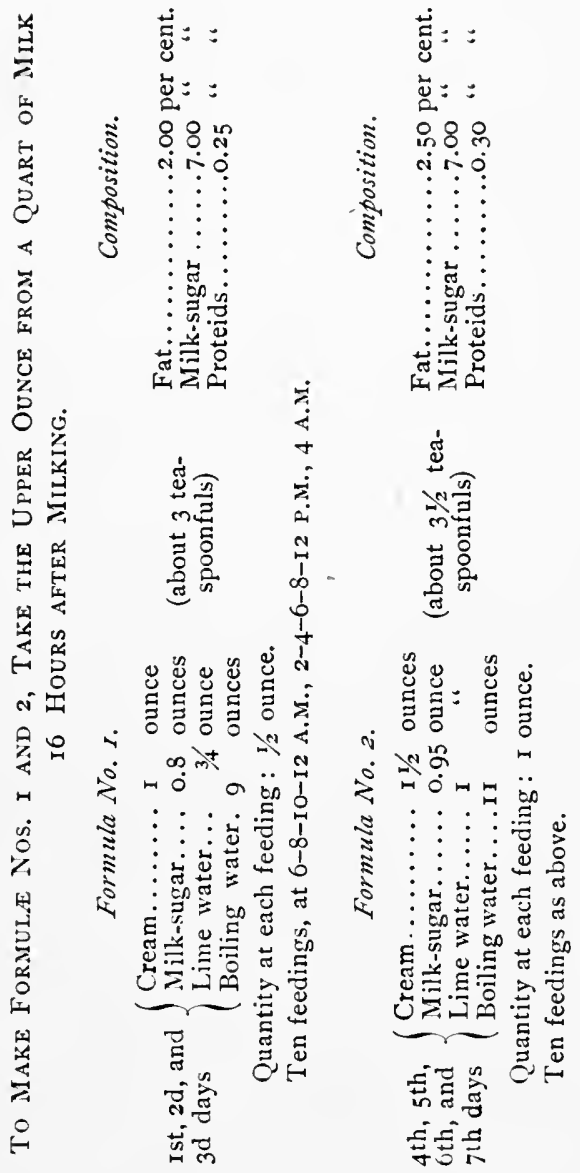




\section{I4 Feeding of Infants}

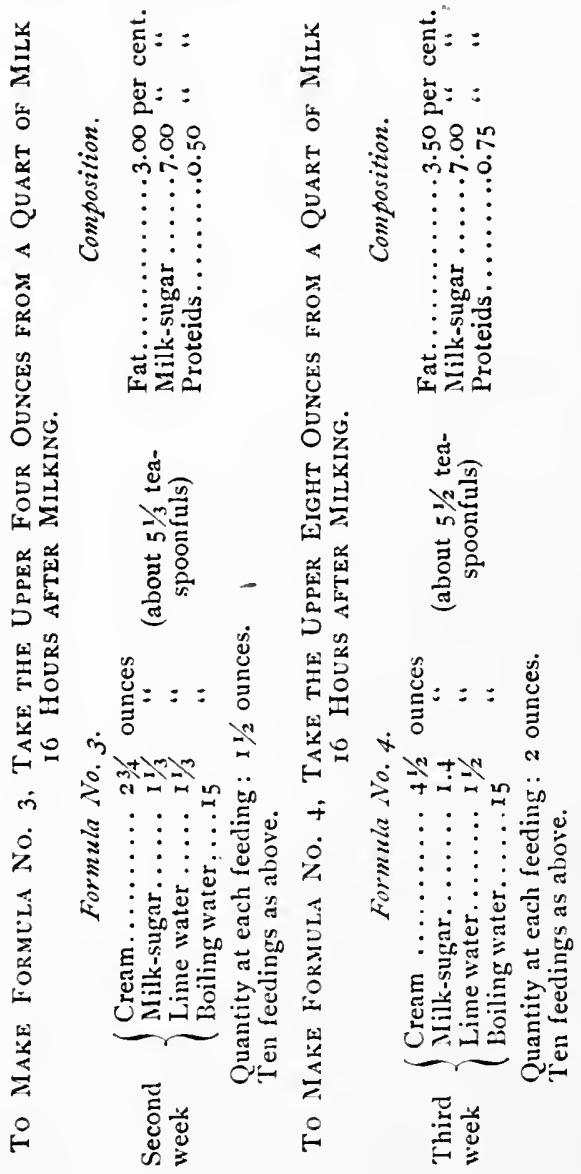




\section{Modifying Milk}

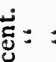

茫:

हิ 888

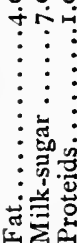

sis

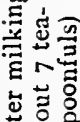

至的泀

品

官总: 齐

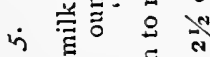

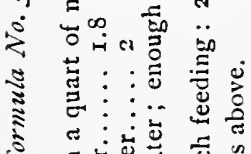

है

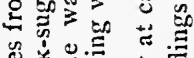

它影

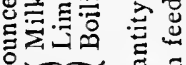

二 总焉

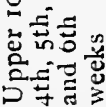

迡: :

岸: :

88 웅

+ri

: : :

$\vdots$

$\therefore:$

:

:

: กับ

느 훙

究我

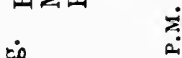

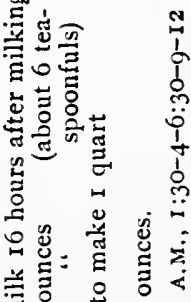

○ 芫

¿ पे

ঊ 节

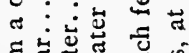

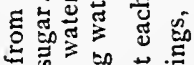

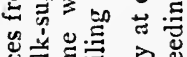

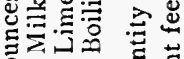

詿这

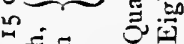

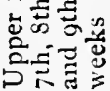




\section{I6 Feeding of Infants}
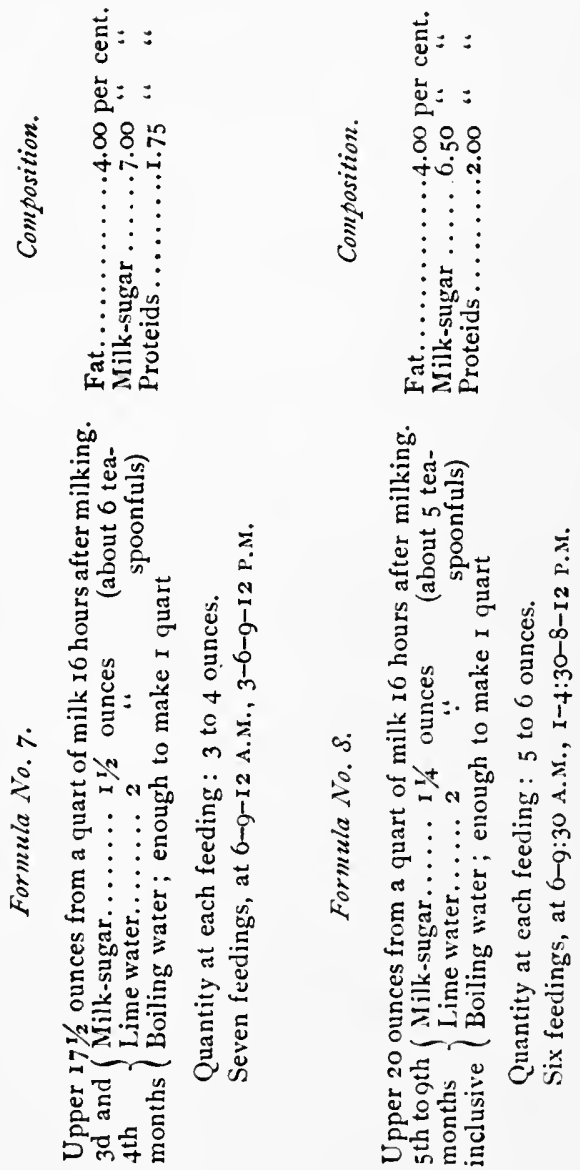
Modifying Milk

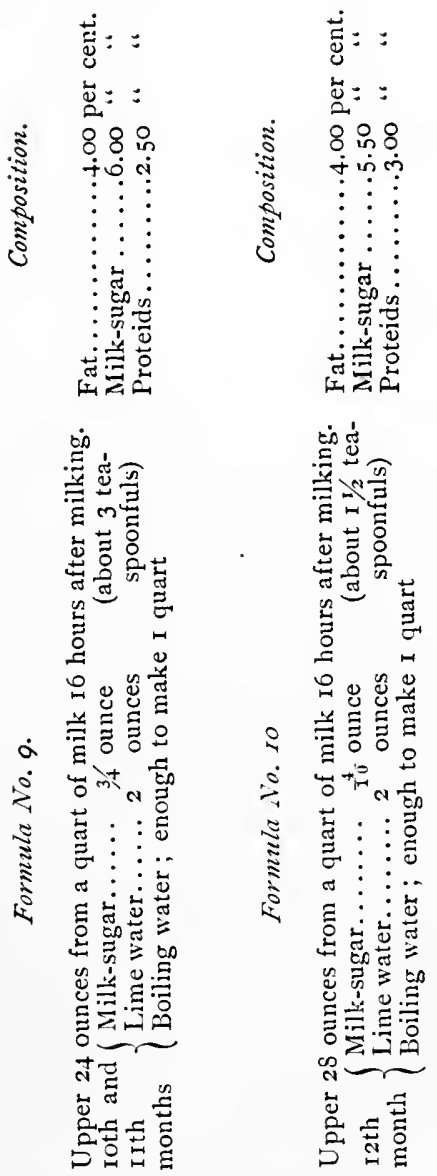


18 Feeding of Infants

The above formulæ are computed for milk of good quality, which has been bottled for 16 hours or longer. Nearly all of the fat will then have risen into the upper 8 or 9 ounces. Hence the amount of fat contained in the mixtures made by the above formulæ will be proportional to that of the original milk, and will vary with the richness of the latter.

With milk from the same source, however, the composition would probably be as constant as that of mother's milk, and the gradation of composition from that of human milk to that of the cow's milk used in making the mixtures would be easy and regular. Children get over slight chemical differences in cow's milk much more readily than they do physical differences-those due 


\section{Modifying Milk}

to contamination. This is abundantly proven by analyses of woman's milk where chemically it was far from correct, yet the nurslings were thriving.

After preparing the food, it should be put in as many bottles as there are feedings for the 24 hours, each bottle containing the amount for one feeding ; the bottles are then stoppled with sterilized cotton, placed in the nursery refrigerator until wanted, and kept at a temperature of $45^{\circ}$ to $50^{\circ} \mathrm{F}$.

There are two unmistakable and unerring guides regarding the quantity of food for each feeding, namely, the capacity of the stomach of infants, and the amount of milk secreted by the breasts of a healthy nursing woman. The former was ascertained with great accuracy by 
$20 \quad$ Feeding of Infants

Frolowsky, of Russia, the latter by Prof. J. Forsyth Meigs, of Philadelphia, and Prof. J. Lewis Smith, of New York. The results of the investigations of these three men have been taken as the standard guides of writers.

CAPACITY OF STOMACH IN INFANTS. (Frolowsky) :

\begin{tabular}{cccc} 
Age & Capacity & Age & Capacity \\
Week. & in ounces. & Week. & in ounces. \\
Ist & I & 12th & $3 \frac{1}{3}$ \\
4th & $2 \frac{1}{2}$ & 16th & $3 \frac{4}{7}$ \\
8 th & $3 \frac{1}{5}$ & $20 t h$ & $3 \frac{3}{5}$ \\
\multicolumn{4}{c}{ OVER-FEEDING. }
\end{tabular}

Over-feeding is one of the greatest banes of bottle-fed children, and causes more indigestion and ill health than is generally believed, even by physicians.

After the first few weeks of life the stomach should rest for several hours at night. With a 
Modifying Milk

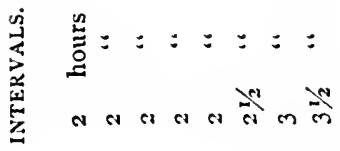

足

留

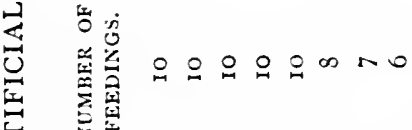

学

怘

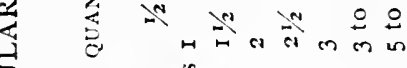

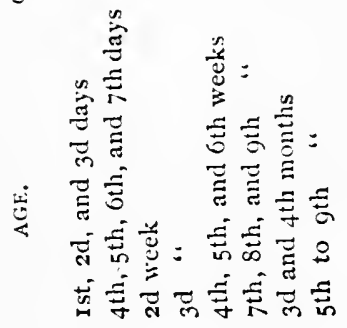




\section{Feeding of Infants}

little care and patience, the child can be taught the habit of being fed at definite periods, and will waken for its meals with wonted regularity.

A weekly gain in weight is the best indication that the infant is being properly nourished. During the first half year, the normal weekly gain is about four ounces; during the next six months, a little less. A properly fed child is satisfied after taking its bottle, and will fall asleep until the next feeding. Over-feeding is indicated by a restless, wakeful state, caused by indigestion. The mother or nurse frequently ascribes these symptoms to hunger, and the child is fed whenever it cries, the disturbed digestion being aggravated thereby.

The danger of giving too little 
food is infinitesimal, as compared to the danger of giving too much.

Some infants have individual peculiarities concerning their food. Such cases require the attention of the family physician. No deviation from the rules for feeding should ever be made without consulting a physician.

TO HEAT THE FOOD.

Place the bottle in a vessel provided for the purpose (see list, pages 26 to 30), containing tepid water; heat it gradually by means of an alcohol flame, or a . Bunsen gas-burner, until the milk is from $99^{\circ} \mathrm{F}$. to $102^{\circ} \mathrm{F}$, as tested by a dairy thermometer.

The milk is kept warm during the feeding, by placing the bottle in a flannel case, closed at the top with a draw-string. 


\section{Feeding of Infants}

POSITION DURING FEEDING.

The infant should lie on the arm of the attendant, in the position it would be in taking the breast. This semi-erect position diminishes the risk of strangulation, and the milk is less likely to be regurgitated ; the stomach of the infant being almost vertical, and having no muscular ring to protect it at the upper end, where the esophagus, or gullet, opens into it.

TIME ALLOWED FOR FEEDING.

The nursing infant is about fifteen to twenty minutes in taking its meal; the bottle-fed child should take about the same time. Rapid feeding is a common cause of indigestion in hand-feeding.

After feeding, the child should 


\section{Modifying Milk}

be put in its crib and kept quiet. It must not be carried about, swung in the air, jolted in the lap, or shaken in its carriage. Many cases of serious vomiting in infants have had as their sole cause these inane, jig-jog, dandling movements.

\section{BOTTLES.}

The bottles should be graduated, of transparent flint glass, cylindrical in shape, with a wide neck. They should be of two sizes, of four and eight ounces. There should be as many in use as there are feedings in the twenty-four hours.

After each feeding, the bottle should be thoroughly rinsed with cold water, then filled with cold water and bicarbonate of soda (teaspoonful to pint). Immediately before putting milk in them, 
26 Feeding of Infants

they should be placed in a vessel and boiled in filtered water for ten minutes.

NIPPLES.

Black rubber conical nipples, with a single small hole, are the best.

Immediately after using, they should be washed with warm water and borax (teaspoonful to pint), turned inside out and thoroughly cleansed, then placed in a glass bowl (kept exclusively for the purpose), and filled with sterilized water; this is to be frequently renewed.

Immediately before using, they should be put in boiling water for a moment.

\section{EQUIPMENT.}

In order to secure satisfactory results in home modification of 


\section{Modifying Milk}

milk, too great stress cannot be laid upon the selection of appropriate articles with which to work. These should be, as far as possible, of glass, aluminum, or of such ware as is of a smooth surface.

A table used solely for this purpose should be kept in a light and airy room.

A glass case for the smaller articles is commended, while a glass top to the table is a further security against germs.

Each article should be absolutely essential and practical.

A large tray should be set upon the table, and the following things should be on it, or at hand in the case, ready for immediate use :

A small dipper holding $\frac{1}{2}$ ounce, to take out, without displacing it, the top cream from a quart bottle of milk. 
28 Feeding of Infants

A double boiler, one section to be used for mixing the feedings, while the second section may be used for heating water (later this utensil may be used for preparing the child's cereals).

Three jars, to contain respectively milk-sugar, borax, bicarbonate of soda. Each jar to be distinctly marked.

Two quart bottles, to contain lime water and alcohol. The bottles to be plainly lettered.

A spirit lamp (a French model is the safest).

A Bunsen gas-burner.

A tablespoon.

A teaspoon.

A funnel (with large mouth to insure cleanliness).

I dozen 4-ounce flint glass graduated bottles.

$\frac{1}{2}$ dozen 8-ounce flint glass graduated bottles. 


\section{A box of sterilized cotton.}

A stand to hold ten bottles.

An 8-ounce measuring glass.

A flat-bottomed narrow vessel, to contain water, in which to place a bottle while heating milk.

A dairy thermometer.

A box of black rubber "Home" nipples.

A small glass bowl, in which to keep two nipples in use.

Flannel cases, in which to place bottle, to keep milk warm while infant is feeding.

A glass jug, to contain filtered sterilized water.

A basin in which to "wash up."

A set of wash cloths.

A set of dish towels.

A small pail for waste water.

A nursery refrigerator.

A table with complete equip- 
$30 \quad$ Feeding of Infants

ment for infant feeding, known as "The Noel Nursery Table," has recently come to my notice, and is a valuable adjunct to the nursery for artificial feeding.

\section{MILK SUPPLY.}

Uncontaminated milk is necessary for successful infant feeding. Contaminated milk, however carefully modified or pasteurized, will cause disordered digestion in the young child. It is pertinent, therefore, briefly to consider the conditions which are essential for the supply of pure milk.

Mixed milk from a herd is preferable to the milk from one cow, as it is more uniform in composition.

The herd must be regularly subjected to the tuberculin test, to exclude tubercular cattle. 


\section{Modifying Milk}

The cows must be groomed before milking, and the udders and teats washed and dried.

The milkman's hands must be sterilized before milking. $\mathrm{He}$ must wear clean, washable clothes while milking; wash his hands before milking each cow, and keep them dry while milking.

The cows must be milked in a building provided for the purpose, apart from the stables.

The milking must be done into sterilized quart glass bottles; the milk should at once be cooled to a temperature of $40^{\circ}$ F.; the bottles immediately sealed and labelled across the cap, with the name of the dairyman and the date of the milking. This provision facilitates investigation, should the milk be suspected as the source of contagious disease. 
$32 \quad$ Feeding of Infants

Any person living in a house where there is contagious disease, or who may in any wise be exposed, directly or indirectly, to contagion, must not have anything to do with the dairy, or the handling of the milk.

In the event of contagious disease appearing on the farm, the patrons must be notified at once, and the milk supply discontinued, although still paid for.

This precaution obviates temptation to conceal the existence of contagion.

\section{PASTEURIZATION.}

It is a popular belief that pasteurization makes cow's milk, even if fresh and pure, a more suitable food for infants. This is erroneous: Fresh, pure milk is not improved by pasteurization; it is not more digestible, 


\section{Modifying Milk}

and it is in no way a better food for an infant.

Does pasteurization deteriorate fresh milk? I have seen scurvy where pasteurized, modified milk had been the only food. Recovery was rapid with the continued use of the same food, raw.

A physician told $m e$ in the autumn of 1898 that he had three cases of scurvy during that summer in his practice-one his own child. All three children had been fed on modified milk, pasteurized.

What is the aim of pasteurization?

First : To destroy disease germs in milk.

Second: To enhance its preservation-to prevent its turning sour.

Where the practicable rules for providing a pure milk supply 
$34 \quad$ Feeding of Infants

are effective, pasteurization for the destruction of disease germs is unnecessary.

Preservation of milk. Experiments at the Yale University Agricultural Experiment Station have fully proved that when milk is cooled immediately after milking to a temperature of $40^{\circ} \mathrm{F}$., all bacteria growth is at once arrested, and continues so, if the milk is kept at a low temperature. Under such conditions milk will keep sweet three weeks. This has been done in this country and also in England.

By medical supervision of the milk production, it is practicable to remove wholly the danger (never a frequent one) of contagious disease germs; and by scrupulous cleanliness in handling the milk, and keeping it at a temperature of $40^{\circ} \mathrm{F}$., milk 
may be secured, having all the advantages claimed for pasteurized milk, without any of its disadvantages.

At the meeting of the American Pediatric Society, June, I899, Prof. Forcheimer stated: "Our ideal food in the future is going to be raw milk."

Prof. T. M. Rotch says : "The endeavor should always be made to prevent impurities from getting into the milk, in preference to trying to eradicate them after they have begun to alter its normal composition."

Pasteurization will not make contaminated milk pure, nor stale milk, fresh. Such milk should never be given to infants; -it ought to be thrown away. Supervision is more of a safeguard than dependence upon pasteurization. 
$36 \quad$ Feeding of Infants

Conclusions. First: Where the production and handling of milk are properly guarded, pasteurization is unnecessary.

Second: Experience with pasteurization demonstrates that when cow's milk is used as a substitute for human milk, absolute freshness is a factor of prime importance.

Third: Fresh, raw milk is superior in nutritive value to that which has been artificially changed by pasteurization.

RECAPITULATION.

We have seen, then, that for the successful substitution of cow's milk for human milk, the following conditions are essential :

First: Pure, fresh milk.

Second: It must be so modified that the proportions of the 


\section{Modifying Milk}

different constituents are made the same as in human milk.

Third: Scrupulous cleanliness.

Fourth : Quantity at each feeding, as indicated by the tables.

Fifth: Semi-erect position during feeding.

Sixth: Feeding slowly.

Seventh : Regularity, as given in schedule.

Eighth : Temperature of food $99^{\circ}$ to $102^{\circ} \mathrm{F}$.

Ninth: After the first few weeks, six or eight hours of rest at night for the digestive organs.

PREDIGESTED FOODS.

Continued use of predigested foods weakens the stomach of an adult by relieving it of work it should do.

Prolonged use of these foods for healthy infants so enfeebles 
$3^{8} \quad$ Feeding of Infants

digestion that it takes years to restore it, if at all.

It should be borne in mind that the digestive powers of the infant need to be developed, and consequently the use of peptogenic milk-powder, or other pepsine preparations, can not be used continuously in healthy infants with impunity:

INFANT FOODS.

Something must be said about the so-called "Infant Foods" which are being so constantly pressed before the attention of mothers by most enticing advertisements.

There is but one standard by which to judge these ubiquitous commercial foods, viz., human milk. The proportions, and the nature of the constituents con- 


\section{Modifying Milk}

tained in it, are the criterion of what an infant's food should be when artificially made.

Tested by this unerring standard, not one of these foods fulfils one of the conditions required of a substitute for human milk.

Prof. Chittenden, of Yale University, Prof. Leeds, of Stevens Institute,' and other chemists, have by repeated analyses demonstrated that every infant food on the market is deficient in fat, milk-sugar, and albuminoid.

The large amount of fat in human milk is conclusive as to its great importance.

Fat serves most important purposes in the nutrition of growing infants,--enters largely into the structure of brain, nerve, and the marrow of bone, and serves as fuel, producing heat and force; every commercial food is 


\section{Feeding of Infants}

strangely destitute of this vital constituent.

What is of more weighty consequence than the relative proportions of the various constituents contained in these foods, is their nature,- the source from which they are derived.

Milk is purely an animal food, of animal origin ; these foods, on the contrary, are vegetable, of vegetable origin.

A food may have high nutritive value at one period of life, at another be useless, or even injurious, owing to inability of the individual to digest it. $\mathrm{Na}$ ture has not endowed infants with digestive power to deal with vegetable products. With profound disregard of this physiological fact, the proprietary foods are almost entirely vegetable.

Albuminoid is the form of 
material in which nitrogen is supplied to the body. Nitrogen enters into the structure of every cell. The blood and all the tissues of the body are formed by cells. Nitrogenous matter is essential to every vital process, consequently the growing child requires more albuminoid in proportion to its weight than the adult. These foods contain as a substitute for the albuminoid of milk, nitrogenous material derived from barley or other grain. Vegetable albuminoid and animal albuminoid are not identical.

Vegetable albuminoid must undergo transformation into animal albuminoid before it can be utilized for the purpose of cell growth,- - for the structure of brain, nerve, muscle. Vegetable albuminoid is more difficult of digestion and assimilation than 
animal albuminoid; despite this fact, manufacturers offer it to the delicate, hitherto untried digestive organs of the infant.

A child exclusively fed on any one of these foods has but one chance in fifty with a milk-fed child in a battle with acute dis-. ease.

These foods are all deficient in milk-sugar.

Human milk contains 7 per cent. of this constituent from the beginning to the end of the nursing period. Milk-sugar is readily assimilable, and undergoes direct transmutation into animal heat. The imperfectly developed nervous system of the infant produces little heat. Nature has made provision for the undeveloped heat centre in the infant by the large amount of animal sugar supplied to it in its dietetic 
birthright. Manufacturers have substituted for this animal constituent, starch, dextrose or maltose. The vegetable substitutes are difficult of digestion and assimilation, and in many instances produce digestive or other disturbances, instead of supplying animal heat.

The proportion of fat, sugar, and albuminoid contained in these foods is wholly immaterial. The nature of these constituents and the entire absence of animal element disqualify them absolutely as substitutes for human milk.

Milk is formed from the blood; its composition is closely allied to blood. The water passes from the minute blood-vessels into the milk ducts, carrying with it the mineral constituents in solution, and part of the albumin of blood. 


\section{$44 \quad$ Feeding of Infants}

The larger part of the albumin is changed during its passage, and appears as caseine, the albuminoid of milk.

For this secretion from the blood-this "blanched blood"it is endeavored to substitute a vegetable product.

Milk is a living fluid, and differs from all mixtures advertised as substitutes in that the process of manufacture, by which they have been rendered capable of being preserved, has converted them into dead material.

Neither chemistry, nor commerce, will ever be able to place on the market a product which will fulfil the conditions required of a substitute for this living fluid, freshly secreted from the blood.

Fresh food is required at every period of life.

We all know that scurvy is a 


\section{Modifying Milk}

sequence of a diet of salt or canned provisions. Infants also are liable to scurvy from the protracted use of preserved foods, such as condensed milk, dried milk preparations, or any of the so-called "Infant Foods." I have seen over sixty cases of scurvy, every one of them being due to the prolonged use of commercial foods, or of over-heated milkwhich is a preserved food.

Most of these cases were in the country, where fresh milk was almost at the door.

One extreme' case was that of a child sixteen months old, whose father had eight hundred acres of fertile land and a large dairy ; the baby had never tasted milk! Recovery was complete on WalkerGordon "Modified Milk"-not pasteurized-without other treatment. 
$46 \quad$ Feeding of Infants

The hospitals and dispensaries in this country, and in Europe, furnish irrefutable evidence that the enormous difference in mortality between naturally and artificially fed children is due to the extensive use of these foods.

With our present enlightenment, it seems inexplicable that in the past many physicians of high attainments recommended commercial foods. The explanation is, that not knowing the composition of human milk, they could not know how to modify cow's milk as a substitute for it. The discovery of the accurate composition of woman's milk contains the seminal principle of the modification of cow's milk. From one to the other is a natural step in infant feeding. Modified milk is the inevitable consequent of Meigs' discovery. 
His enlightenment will eventually eliminate preserved foods forever from the nursery.

This discovery, with its happiest results and full fruition, will cause the total disappearance of rickets and scurvy in infants; a diminution of the gastro-intestinal diseases ; a lowered mortality from all the acute diseases; a higher degree of health, and therefore of happiness and usefulness, of every artificially fed child.

Meigs' discovery, when fully appreciated by physicians and mothers, will be the means of saving more lives than any other discovery made by medical science during the nineteenth century, as it will affect more or less the life and health of every child born into the world. 



